\title{
The distribution of Symbiodinium diversity within individual host foraminifera
}

\author{
S. A. Fay $\cdot$ M. X. Weber $\cdot$ J. H. Lipps
}

Received: 8 August 2008/Accepted: 8 May 2009/Published online: 5 June 2009

(C) The Author(s) 2009. This article is published with open access at Springerlink.com

While one-to-one specificity between reef-dwelling hosts and symbiotic dinoflagellates of the genus Symbiodinium may occur, detailed examination of some hosts reveals that they contain multiple symbiont types. Individuals of the foraminifer Amphisorus hemprichii living in Papua New Guinea contained mixed communities of Symbiodinium dominated by symbiont types in clades $\mathrm{C}$ and F. Moreover, the types showed a distinct pattern in their distribution across the radius of the foraminifer, with clade F Symbiodinium more prevalent in the center of the host cell. The mixed community of symbionts and their pattern of distribution within the foraminifer is likely the result of processes happening both inside the foraminifer and in its external environment. Persistent mixed symbiont communities in foraminifera may be stabilized through benefits conferred by maintaining multiple symbiont lineages for symbiont shuffling. Alternatively they may be stabilized through a heterogeneous internal host environment, partitioning of symbiont functional roles or limitation of symbiont reproduction by the host. Six factors generally determine the presence of any particular symbiont type within a foraminifer: mode of transmission, availability from the environment, recognition by the host, regulation

Communicated by Biology Editor Dr. Ruth Gates

Electronic supplementary material The online version of this article (doi:10.1007/s00338-009-0511-y) contains supplementary material, which is available to authorized users.

\footnotetext{
S. A. Fay $(\bowtie) \cdot$ M. X. Weber · J. H. Lipps

Department of Integrative Biology

and Museum of Paleontology,

University of California,

Berkeley, CA 94720, USA

e-mail: safay@berkeley.edu
}

by the host, competition between lineages, and fitness of the holobiont.

Keywords Symbiodinium - Symbiosis - Foraminifera . Amphisorus hemprichii $\cdot$ Ecology $\cdot$ Coral reef

\section{Introduction}

The formation and persistence of modern coral reefs depends largely on organisms that host dinoflagellate algal symbionts of the genus Symbiodinium. Symbiodinium displays wide genetic diversity, both within its many hosts and across multiple spatial scales (Baker 2003; Coffroth and Santos 2005; Stat et al. 2006). This diversity groups into eight clades, lettered A through $\mathrm{H}$, and within each of these clades further genetic diversity represents ecologically distinct lineages of Symbiodinium, hereafter referred to as "types" (reviewed in Coffroth and Santos 2005). Phenotypic differences exist between different clades, such as susceptibility to bleaching or physiological variation under different light and temperature conditions (Kinzie and Chee 1979; Rowan et al. 1997; Rowan 2004). Different Symbiodinium types within a clade are also ecologically distinct and are differentially distributed over factors such as biogeography, habitat, host type, and host ontogeny (LaJeunesse et al. 2004; Rodriguez-Lanetty et al. 2004; Sampayo et al. 2007). Temporary shifts in symbiont type following environmental perturbations are also known (Thornhill et al. 2006). However, many of the biological factors that influence the composition of Symbiodinium lineages within an individual host remain to be discovered.

Characterization of the diversity of Symbiodinium has frequently assumed that an individual host contains only a single physiologically or ecologically important symbiont 
lineage. Some methods used to genetically identify Symbiodinium types, such as direct sequencing and Denaturing Gradient Gel Electrophoresis (DGGE), can fail to recognize low levels of alternate Symbiodinium genotypes in an individual sample (Apprill and Gates 2007). In studies on corals using methods which are explicitly designed to identify mixed genotypes, such as FISH and real-time Q-PCR, a mix of symbionts is commonly found (Loram et al. 2007). Intragenomic variation at the ribosomal rRNA locus potentially confounds the interpretation of multiple rRNA haplotypes (especially in the ITS regions) as multiple independent lineages, or types, of Symbiodinium (Thornhill et al. 2007). Fortunately, the extent of this intragenomic variation does not appear to obscure the signal from sequence differences seen between the different clades (Sampayo et al. 2009).

Mixed symbiont communities do appear to be common in some corals (Baker and Romanski 2007). In one study, four species of coral that previously were thought to possess only a single clade were shown to harbor multiple clades of Symbiodinium in nearly $80 \%$ of the individuals sampled (Mieog et al. 2007). Non-coral host individuals may also commonly host multiple clades; for example, individuals of certain species of tridacnid clams harbor multiple symbiont clades (Carlos et al. 2000).

An important component of reef communities, symbiont-bearing foraminifera produce on average nearly $5 \%$ of the carbonate deposited on coral reefs, and up to $25 \%$ on some reefs (Langer et al. 1997). They host a more genetically diverse assortment of symbiont types than most coral species (Pochon et al. 2007), supporting a hypothesis that they may be a reservoir for Symbiodinium diversity in the reef community. While most Symbiodinium hosts, such as corals, clams, and sponges feed primarily from the seawater flowing over a reef, foraminifera feed directly from the surface upon which they live (see video in electronic supplementary material), and thus may directly interact with the benthic Symbiodinium community.

Symbionts of soritid foraminifera were recognized early on as cytologically similar to the zooxanthellae of corals and clams (Doyle and Doyle 1940). The first published sequences from Symbiodinium found in foraminifera showed that the symbionts are genetically similar to those found in corals (Langer and Lipps 1995). Since then, Xavier Pochon and his colleagues have described in detail the genetic diversity of Symbiodinium found in these foraminifera (reviewed in Pochon and Pawlowski 2006), examining factors such as host specificity (Pochon et al. 2001; Garcia-Cuetos et al. 2005), biogeographic distribution (Pochon et al. 2004), and local ecology (Pochon et al. 2007). Analysis of Symbiodinium from foraminifera using DGGE indicates that $15 \%$ of samples from Guam had mixed symbiont types (Pochon et al. 2007), but an explicit study of symbiont heterogeneity in foraminifera has, until now, not been done. Thus, the first aim of this study was to examine more closely the symbiont composition within individual foraminifera.

The second aim of this study was to see whether the symbiont composition is distributed evenly within an individual foraminifer. The cytoplasm of a soritid foraminifer is not a homogenous mix of its contents. The test is divided into chambers, and the apertures between the chambers allow the foraminifer to partition its cytoplasm into different zones (Fig. 1, adapted from Muller-Merz and Lee 1976). Algal symbionts are found throughout the host. Foraminiferal nuclei are concentrated in the central zone

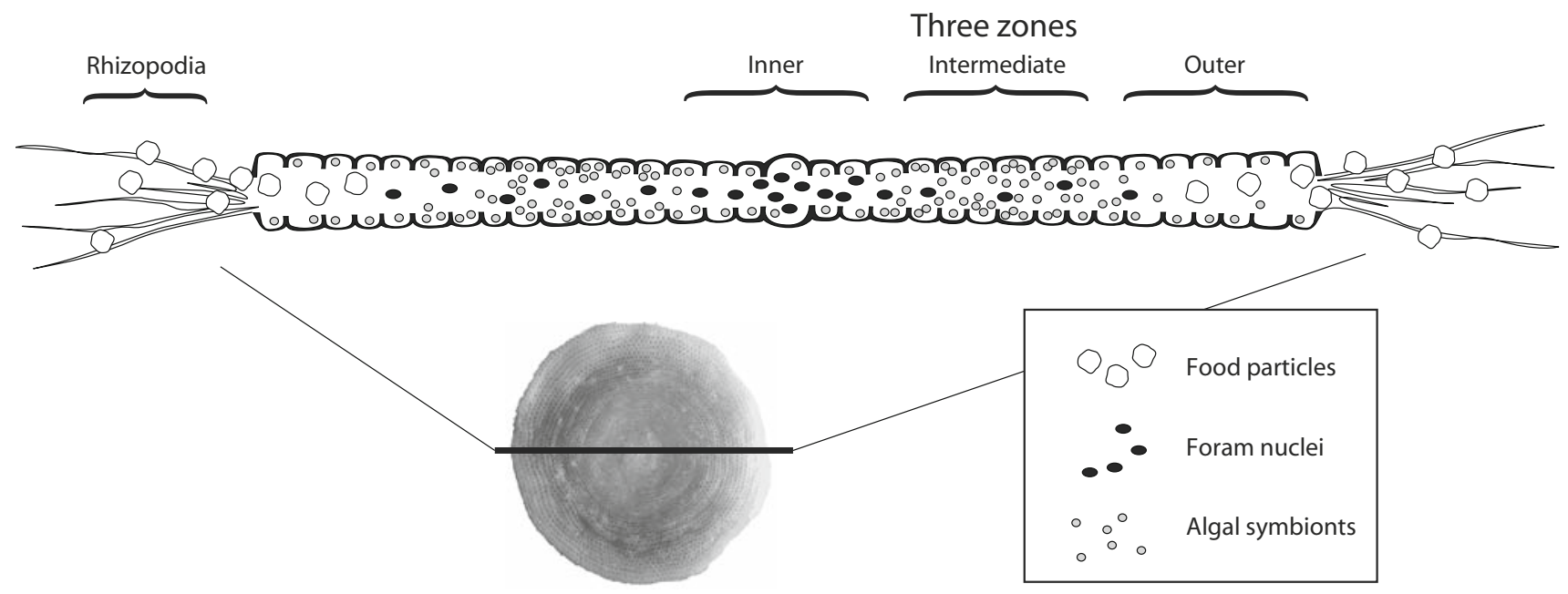

Fig. 1 A cross-section diagram of a soritid foraminifer, adapted from Muller-Merz and Lee 1976. The test can be divided into three zones: (1) the inner zone, with some symbionts but mostly foraminiferal nuclei, (2) the intermediate zone, with some foram nuclei but mostly symbionts, and (3) the outer zone, with some symbionts but also food particles being digested 
and the zone along the edge has many food vacuoles. The symbionts are most densely packed in the intermediate zone, which appears as a darker circle, giving the discoidal foraminifer a bulls-eye appearance. These three zones suggested a sampling strategy to see if different symbiont types occur in different parts of the foraminifer.

\section{Methods}

Field site and collection

In August of 2005, on SCUBA, Amphisorus hemprichii foraminifera were hand-collected into Ziploc bags from the forereef on the Pacific Ocean side of Nusalik Island, near Kavieng, New Ireland Province, Papua New Guinea. The foraminifera were collected in two areas approximately $1 \mathrm{~km}$ apart $\left(2^{\circ} 34^{\prime} 26^{\prime \prime} \mathrm{S}, 150^{\circ} 46^{\prime} 26^{\prime \prime} \mathrm{E}\right.$ and $2^{\circ} 34^{\prime} 58^{\prime \prime} \mathrm{S}$, $150^{\circ} 46^{\prime} 15^{\prime \prime} \mathrm{E}$ ). Within each area three samples were collected, one each at 20,12, and $6 \mathrm{~m}$ deep. Ten minutes at each depth was spent collecting as many soritid foraminifera as possible, typically more than 30 individuals. All A. hemprichii foraminifera collected were $3-6 \mathrm{~mm}$ in diameter. In the laboratory, 16 individuals from each sample were brushed clean in filtered seawater then broken in half. One half was placed into tubes with RNAlater nucleic acid stabilization reagent (Qiagen), and the other half was dried for morphological identification.

\section{Extraction and PCR}

In the laboratory, from each foraminifer three samples of approximately $1 \mathrm{~mm}^{3}$ were taken, one from each zone: inner, intermediate, and outer. Extracts were made from each sample using a guanidinium-based protocol (adapted from Sambrook et al. 1989). Three foraminifera from each depth in the two sampling areas were examined; nine foraminifera total were examined, six from one area and three from the other.

Dinoflagellate nuclear DNA from the rRNA locus (ITS1-5.8S-ITS2-partial 28S) was PCR amplified using an MJ PTC-200 thermocycler with the program $\left(94^{\circ} \mathrm{C}\right.$ $3: 00 \mathrm{~min}, 64^{\circ} \mathrm{C} 1: 30 \mathrm{~min}, 35 \mathrm{~s} \times\left(72^{\circ} \mathrm{C} 2: 00 \mathrm{~min}, 94^{\circ} \mathrm{C}\right.$

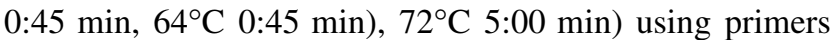
S_DINO and L_O (Pochon et al. 2001) and the enzyme AmpliTaq Gold (Applied Biosystems) with manufacturer's recommended reagent concentrations.

Cloning and sequencing

PCR products $(N=27)$ were cloned using a TOPO TA cloning kit (Invitrogen K250020). Twenty-four colonies from each reaction were picked and cultured in $4 \mathrm{ml}$ of LB + Kanamycin overnight, centrifuged, and plasmid was extracted from pelleted bacteria using the phenolchloroform protocol (Sambrook et al. 1989). Extracted plasmid was quantitated and checked for correct size insert on a $0.8 \%$ agarose gel/TBE. From eight clones per reaction, plasmid with correct size insert was sequenced on an ABI 3730 capillary sequencer using S_DINO as a primer. In total, 199 clones were sequenced since some of the cloning reactions resulted in fewer than eight clones.

Analysis

The resulting clone sequences were first examined using MEGA-BLAST (http://www.ncbi.nlm.nih.gov/blast). Some $(5 / 199,<3 \%)$ of the sequences were discarded because they were identified as pseudogenes based on large deletions in rRNA-coding regions (Thornhill et al. 2007; Scott Santos pers. comm.). All of the remaining clone sequences were aligned with MUSCLE (Edgar 2004) and checked by eye. Since phylogenetic inference software for DNA sequences can only handle gaps as either a fifth character state or missing data, gaps and their associated poorly aligned sequence segments were then removed using GBLOCKS (Castresana 2000). The resulting 194 aligned clone sequences were analyzed with TCS (Clement et al. 2000) using a 95\% statistical parsimony criterion.

The original sequences of the resulting five ancestral haplotypes (representing the clusters) were then aligned (using MUSCLE + GBLOCKS) to representative sequences from the literature (see Table 1 for GenBank accession numbers). A phylogeny was inferred from this new alignment using MrBayes 3.1.2 (Huelsenbeck and Ronquist 2001), substitution model GTR + I + gamma as determined by ModelTest (Posada and Crandall 1998), for $1.2 \times 10^{6}$ generations, discarding $2 \times 10^{5}$ generations as burn-in.

In order to identify and name the ancestral haplotypes, their ITS2 sequences were aligned (using MUSCLE) to those sequences found in Pochon et al. (2007), wherein the most fine scale diversity of ITS2 types to date has been described. Pairwise distance to the closest match sequence was calculated to quantify homology.

The individual haplotype clusters were interpreted as distinct types of Symbiodinium. Symbiont type versus depth, area, and intracellular host zone were visualized using JMP 7.0 software (SAS Institute, Inc.). The null hypothesis that symbiont type and host zone are independent variables was tested using the Pearson's chi-square statistic. 
Table 1 List of unique rRNA ITS2 haplotypes found in the 9 foraminifera; Clone ID corresponds to the ID numbers in Fig. 2, Cluster ID represents the ancestral sequence identity of the TCS

\begin{tabular}{|c|c|c|c|c|c|c|c|c|c|c|c|}
\hline Clone ID & $\begin{array}{l}\text { GenBank } \\
\text { Accession }\end{array}$ & $\begin{array}{l}\text { Cluster } \\
\text { ID }\end{array}$ & $\begin{array}{l}\text { No. of } \\
\text { clones }\end{array}$ & $\begin{array}{l}\text { Clone } \\
\text { ID }\end{array}$ & $\begin{array}{l}\text { GenBank } \\
\text { Accession }\end{array}$ & $\begin{array}{l}\text { Cluster } \\
\text { ID }\end{array}$ & $\begin{array}{l}\text { No. of } \\
\text { clones }\end{array}$ & $\begin{array}{l}\text { Clone } \\
\text { ID }\end{array}$ & $\begin{array}{l}\text { GenBank } \\
\text { Accession }\end{array}$ & $\begin{array}{l}\text { Cluster } \\
\text { ID }\end{array}$ & $\begin{array}{l}\text { No. of } \\
\text { clones }\end{array}$ \\
\hline 159 & EU785998 & $\mathrm{C} 1$ & 1 & 353 & EU786046 & $\mathrm{C} 1$ & 2 & 569 & EU786108 & F3.5 & 1 \\
\hline 165 & EU786001 & $\mathrm{C} 1$ & 1 & 358 & EU786047 & $\mathrm{C} 1$ & 1 & 583 & EU786110 & $\mathrm{C} 1$ & 1 \\
\hline 168 & EU786002 & $\mathrm{C} 1$ & 28 & 364 & EU786050 & $\mathrm{C} 1$ & 1 & 588 & EU786111 & $\mathrm{C} 1$ & 2 \\
\hline 178 & EU786004 & $\mathrm{C} 1$ & 1 & 391 & EU786053 & $\mathrm{C} 1$ & 1 & 589 & EU786112 & $\mathrm{C} 1$ & 2 \\
\hline 182 & EU786007 & $\mathrm{C} 1$ & 1 & 393 & EU786054 & $\mathrm{C} 1$ & 3 & 596 & EU786115 & $\mathrm{C} 1$ & 1 \\
\hline 184 & EU786008 & F3.5 & 1 & 394 & EU786055 & $\mathrm{C} 1$ & 7 & 603 & EU786117 & $\mathrm{C} 1$ & 1 \\
\hline 186 & EU786009 & $\mathrm{C} 1$ & 1 & 395 & EU786056 & $\mathrm{C} 1$ & 2 & 612 & EU828666 & $\mathrm{C} 1$ & 3 \\
\hline 187 & EU786010 & $\mathrm{C} 1$ & 1 & 415 & EU786061 & F3.1B & 2 & 623 & EU828667 & $\mathrm{C} 1$ & 4 \\
\hline 190 & EU786011 & $\mathrm{C} 1$ & 2 & 418 & EU786063 & $\mathrm{C} 1$ & 2 & 821 & EU828668 & $\mathrm{C} 1$ & 2 \\
\hline 192 & EU786012 & $\mathrm{C} 1$ & 1 & 423 & EU786067 & $\mathrm{C} 1$ & 1 & 638 & EU828669 & $\mathrm{C} 1$ & 2 \\
\hline 196 & EU786014 & $\mathrm{C} 1$ & 1 & 440 & EU786068 & F3.5 & 1 & 640 & EU828670 & $\mathrm{C} 1$ & 1 \\
\hline 197 & EU786015 & $\mathrm{C} 1$ & 1 & 447 & EU786070 & F3.5 & 1 & 642 & EU828671 & $\mathrm{C} 1$ & 3 \\
\hline 204 & EU786017 & $\mathrm{C} 1$ & 1 & 448 & EU786071 & $\mathrm{F} 3.1 \mathrm{~B}$ & 1 & 659 & EU828672 & $\mathrm{C} 1$ & 1 \\
\hline 207 & EU786018 & F3.6 & 2 & 449 & EU786072 & F3.5 & 1 & 660 & EU828673 & $\mathrm{C} 1$ & 2 \\
\hline 208 & EU786019 & F3.5 & 2 & 450 & EU786073 & F3.5 & 1 & 677 & EU828674 & F3.5 & 1 \\
\hline 223 & EU786022 & F3.5 & 1 & 463 & EU786075 & $\mathrm{C} 1$ & 2 & 679 & EU828675 & F3.5 & 1 \\
\hline 226 & EU786023 & $\mathrm{C} 1$ & 1 & 464 & EU786076 & F3.5 & 1 & 682 & EU828676 & $\mathrm{C} 1$ & 1 \\
\hline 229 & EU786024 & F3.5 & 1 & 466 & EU786078 & $\mathrm{F} 3.5$ & 1 & 706 & EU828677 & $\mathrm{C} 1$ & 1 \\
\hline 230 & EU786025 & F3.5 & 1 & 467 & EU786079 & $\mathrm{C} 1$ & 1 & 710 & EU828678 & $\mathrm{C} 1$ & 2 \\
\hline 232 & EU786026 & $\mathrm{H} 2$ & 1 & 468 & EU786080 & F3.5 & 1 & 715 & EU828679 & F3.5 & 1 \\
\hline 234 & EU786027 & F3.5 & 1 & 470 & EU786082 & $\mathrm{C} 1$ & 1 & 716 & EU828680 & F3.5 & 1 \\
\hline 238 & EU786028 & $\mathrm{H} 2$ & 2 & 487 & EU786083 & $\mathrm{C} 1$ & 6 & 733 & EU828681 & F3.5 & 1 \\
\hline 239 & EU786029 & $\mathrm{H} 2$ & 1 & 489 & EU786085 & $\mathrm{C} 1$ & 1 & 735 & EU828682 & F3.5 & 1 \\
\hline 240 & EU786030 & $\mathrm{H} 2$ & 1 & 490 & EU786086 & $\mathrm{C} 1$ & 4 & 748 & EU828683 & F3.5 & 1 \\
\hline 271 & EU786032 & $\mathrm{C} 1$ & 1 & 494 & EU786088 & $\mathrm{C} 1$ & 1 & 759 & EU828684 & F3.5 & 1 \\
\hline 273 & EU786033 & $\mathrm{C} 1$ & 1 & 513 & EU786090 & $\mathrm{C} 1$ & 1 & 773 & EU828685 & F3.5 & 1 \\
\hline 278 & EU786034 & $\mathrm{C} 1$ & 1 & 517 & EU786093 & $\mathrm{C} 1$ & 1 & 775 & EU828686 & $\mathrm{C} 1$ & 2 \\
\hline 281 & EU786036 & F3.5 & 20 & 519 & EU786094 & $\mathrm{C} 1$ & 1 & 777 & EU828687 & $\mathrm{C} 1$ & 1 \\
\hline 311 & EU786038 & $\mathrm{C} 1$ & 1 & 544 & EU786100 & F3.5 & 1 & 782 & EU828688 & F3.5 & 1 \\
\hline 315 & EU786039 & $\mathrm{C} 1$ & 2 & 545 & EU786101 & F3.5 & 1 & 798 & EU828689 & $\mathrm{C} 1$ & 2 \\
\hline 327 & EU786040 & $\mathrm{C} 1$ & 1 & 559 & EU786102 & $\mathrm{C} 1$ & 1 & 804 & EU828690 & $\mathrm{C} 1$ & 1 \\
\hline 330 & EU786041 & $\mathrm{C} 1$ & 2 & 565 & EU786105 & F3.5 & 1 & & & & \\
\hline 339 & EU786045 & F3.5 & 1 & 568 & EU786107 & F3.5 & 1 & & & & \\
\hline
\end{tabular}

cluster that contains the haplotype, and number of clones indicates how many clones of that unique haplotype were discovered

\section{Results}

Clustering of haplotypes and identity of clusters

The clone sequences were divided by TCS into five different clusters (Fig. 2). These clusters were separated by a greater than 11 base-pair difference, the $95 \%$ parsimony criterion for this data set. No cycles were seen in the networks, which would be evidence for either potential recombination events or chimeras resulting from cloning.

TCS inferred an ancestral haplotype for each cluster (boxed in Fig. 2), which was used to identify and name the 


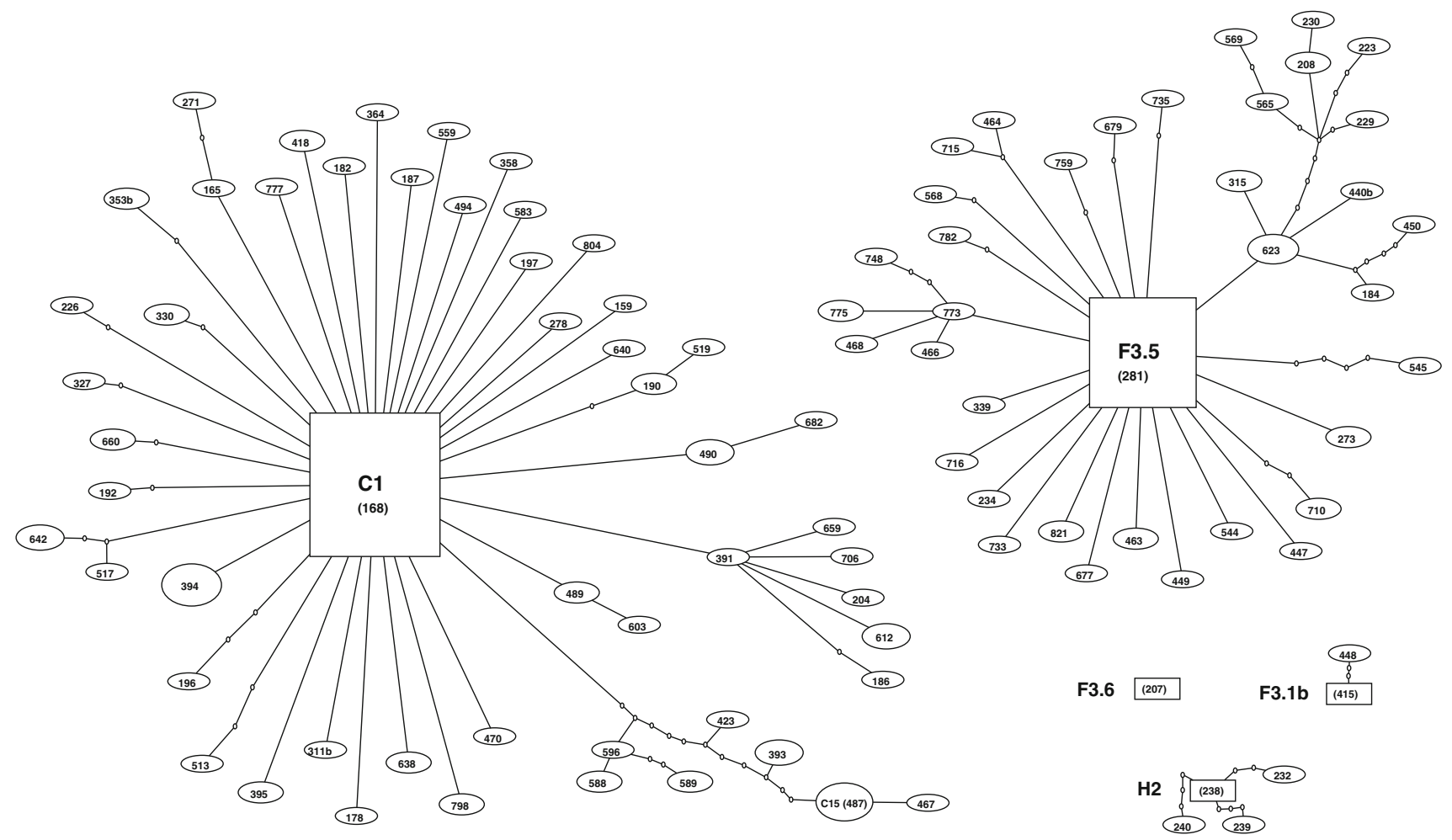

Fig. 2 Unrooted statistical parsimony networks of all clones obtained from the nine foraminifera. Ancestral haplotypes are represented by a box, all others by ovals. The size of the box/oval is proportional to the number of clones with that haplotype. Numbers correspond to clone

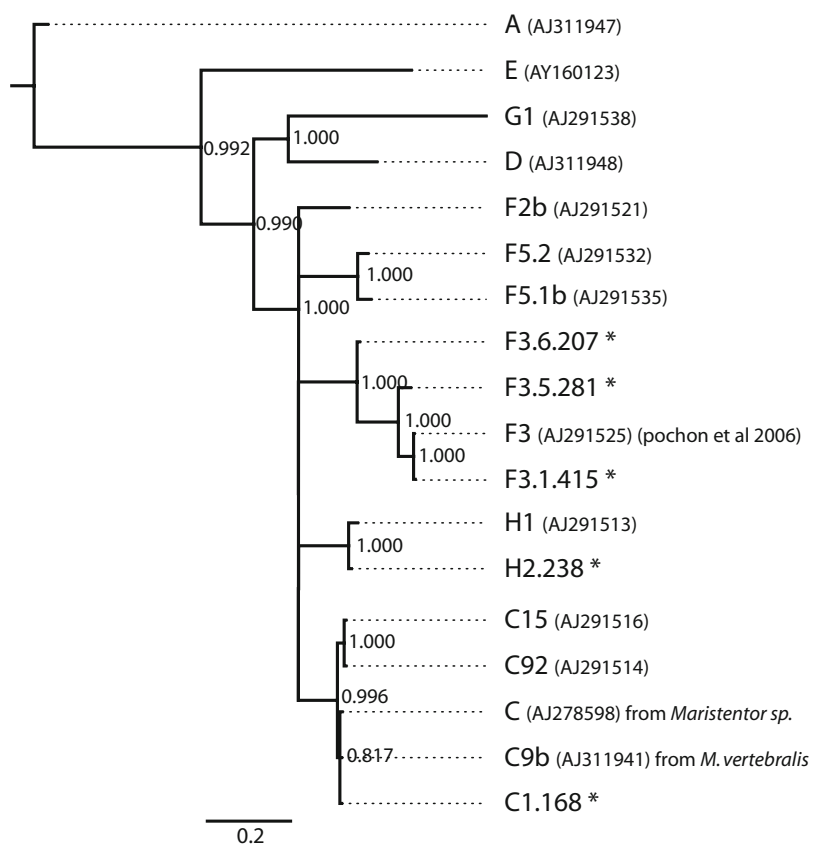

Fig. 3 Ancestral cluster haplotypes, indicated with an asterisk, placed in context of previously identified Symbiodinium haplotypes using Bayesian inference of phylogeny. Branch support indicates Bayesian posterior probabilities; nodes with $<0.75$ support were collapsed. The sequence data is from the rRNA locus: ITS1, 5.8S, ITS2, and partial LSU numbers from Table 1. Symbiodinium type designations follow that of Pochon et al. (2007) except "F3.5" and "F3.6," which are our own designations

closely matches an ITS2 sequence from C1 (AM748551) with $99.6 \%$ sequence identity and is named C1.168. The ITS2 sequence from clone 415 most closely matches F3.1 (AM748565), with 99.4\% sequence identity and it is named F3.1.415. The ITS2 sequences from clones 281 and 207 are similar to but relatively divergent from F3.1 (AM748565), with 95 and $93 \%$ sequence identity, respectively; by extending the (Pochon et al. 2007) classification of types in sub-clade F3 and creating two new sub-clades, they are named F3.5.281 and F3.6.207, respectively.

Symbiont heterogeneity and patterns in distribution

All the foraminifera studied contained a mixed community of symbiont types (Fig. 4a). Each individual hosted at least two clades and one hosted three. The majority of the symbionts found in these foraminifera were of two main types, C1.168 and F3.5.281 (as described by the clusters). Clade H Symbiodinium was found only in the outer and intermediate chambers.

When data from all the foraminifera in this study were combined, a significant $\left(\chi^{2}=34.969, P<0.0001\right)$ pattern was evident across the radius of a foraminifer. Type F3.5.281 was slightly more prevalent than C1.168 in the inner chambers of the foraminifer, but on the edge, $\mathrm{C} 1.168$ 
Fig. 4 Mosaic plots of symbiont genotype distribution. Each vertical bar is proportional to the total number of clones recovered from each haplotype cluster for each sample. a Combined data for each foraminifer $(24 \geq n \geq 20)$. b Combined data for the three host "zones." Clade F types are enriched toward the center ( $n=61$ for inner, 68 for intermediate, 65 for outer, $\left.\chi^{2}=34.969, P<0.0001\right)$
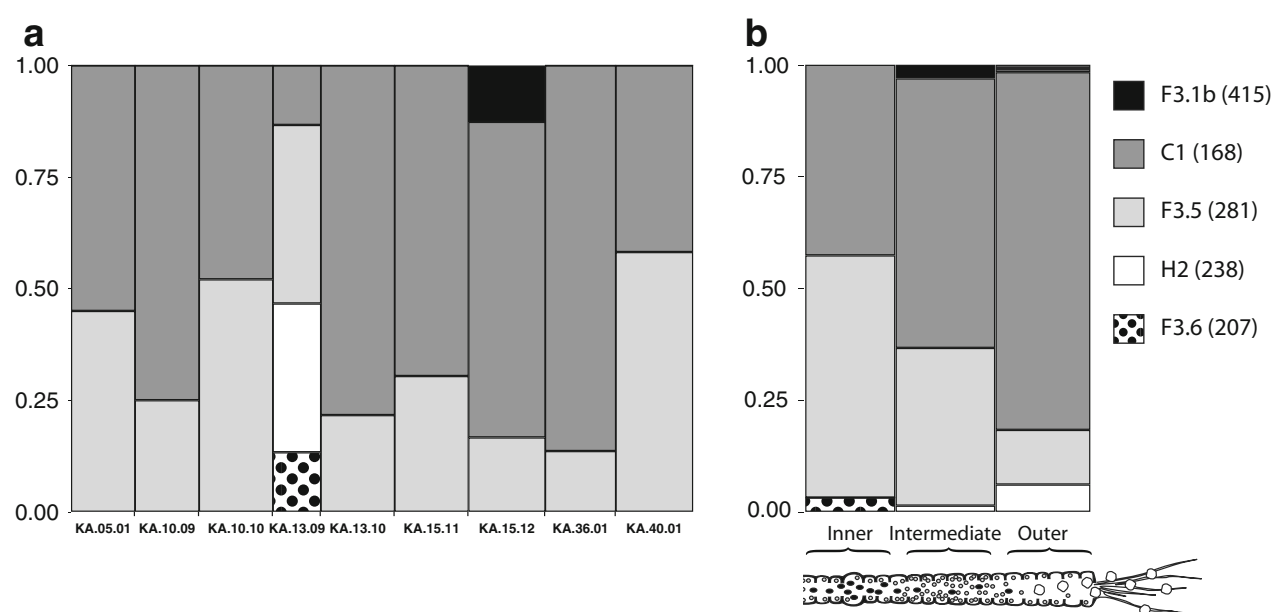

was dominant. The three other types made up a minor part of the total community of Symbiodinium. There was no gradient in Symbiodinium type by depth or significant difference $\left(\chi^{2}=2.414, P=0.2991\right)$ between the two geographic areas.

\section{Discussion}

Symbiont diversity within individual foraminifera

Nine conspecific foraminiferan individuals from a single population in Papua New Guinea showed a great diversity of symbiont haplotypes: 97 different unique haplotypes (ITS1-5.8S-ITS2 rDNA) from within three different clades (Fig. 2). In an earlier study of 1,010 different individual foraminifera from Guam, a high diversity of Symbiodinium ITS2 types from DGGE bands was found, with 61 different types from five different clades (Pochon et al. 2007). Though diversity of cloned PCR products and diversity of DGGE bands are not directly comparable, populations of foraminifera from Guam and PNG both harbor a diverse array of symbionts.

The rRNA locus in Symbiodinium is by far the best represented in the literature to date. However, it has drawbacks as a molecular marker, most particularly its considerable intragenomic variability. In a study of intragenomic variation at the ITS1-5.8S-ITS2 rDNA locus, many of the variants deviated from the dominant haplotype by a single base-pair, with others diverging by multiple base-pair substitutions (Thornhill et al. 2007). The pattern is similar to that seen in this data set (Fig. 2); the clones have many single base-pair differences, likely an artifact of either intragenomic variation or PCR mutations. Since ecologically distinct ITS2 haplotypes can be separated by only a few base-pair changes (LaJeunesse et al. 2004; Sampayo et al. 2009), grouping diverse Symbiodinium ITS-region haplotypes into statistical parsimony networks using TCS is a method that conservatively forms groups which are ecologically distinct (Rodriguez-Lanetty 2003; RodriguezLanetty et al. 2006b; Pochon et al. 2007; Correa and Baker 2009).

All of the individual foraminifera studied contained Symbiodinium of more than one clade (Fig. 4a). The presence of up to three different clades of Symbiodinium within such a tiny host seems remarkable, more so considering that foraminifera are single-celled organisms. Rather than being a phenomenon localized to Micronesia (see Pochon et al. 2007), populations of foraminifera throughout the western Pacific, if not the globe, likely maintain genetically diverse assemblages of Symbiodinium, implicating foraminifera as important reservoirs of symbiont diversity in coral reef ecosystems.

The ability to pair with multiple Symbiodinium types may be normal for hosts with horizontal transmission of their symbionts (Baker and Romanski 2007). The data reported here support this hypothesis. Ecological theory suggests that competition between multiple symbiont lineages destabilizes mutualism by selecting for more virulent, less cooperative strains; this is disadvantageous to the host (Frank 1996). The adaptive bleaching hypothesis and symbiont shuffling together (Buddemeier and Fautin 1993; Baker 2003; Fautin and Buddemeier 2004) provide a possible explanatory counterbalancing benefit to this cost. A heterogeneous mix of symbiont types may offer the host a more flexible response to stress (Rowan 1998). In this model, following adverse environmental change the dominant type is expelled during bleaching, and a low-level background symbiont type multiplies to become the new dominant type since it is more advantageous in the new environment. However, in trying to explain the persistence of mixed symbiont communities within an individual host, alternative hypotheses, such as a heterogeneous internal host environment, distinct functional roles for the different 
symbiont lineages (symbiont niche partitioning), or limitation of symbiont reproduction by the host should also be considered.

Structure in symbiont distribution from outer to inner chambers

The symbionts in these soritid foraminifera show a shift in distribution of Symbiodinium type from the outer chambers to the inner chambers (Fig. 4b). Since the copy number at the nuclear rRNA locus in Symbiodinium spans a wide range and PCR does not amplify DNA in a linear fashion throughout the reaction, these results are not an absolute quantitative measure of the proportions of these symbiont types (Apprill and Gates 2007; Loram et al. 2007; Thornhill et al. 2007). Rather, the data represent a relative measure of symbiont distribution. Several alternative hypotheses can account for what might cause this pattern.

These foraminifera actively feed, and thus may acquire new symbionts from their environment (Lee and Anderson 1991). If a free-living, changing, mixed community of Symbiodinium is present in the environment, the pattern of symbiont distribution in the foraminifer could represent sampling by the host through time. The types near the edge could be those most recently encountered in the environment. Those in the center could have been acquired from an earlier time which have since moved inward. Similarly, the pattern could represent the symbiont mix that was present in the environment when each successive row of chambers formed.

This pattern might also result if the foraminifer were sorting, processing, or otherwise regulating the symbionts as they move inward. The community of symbionts on the edge of the foraminifer may represent the environmental assemblage and those in the center the enriched type(s). Clade C and H Symbiodinium, the lineages that dominate at the edge of the foraminifer, were found free-living in samples of Pacific Ocean seawater (Manning and Gates 2008). Clade F symbionts, which appear to be specialists to foraminifera (Pochon and Pawlowski 2006), are in greater proportion in the innermost chambers. These observations suggest a regulatory enrichment mechanism.

A third mechanism that may explain this pattern is competition or self-sorting of the symbionts within the heterogeneous environment of the host. Different parts of the foraminifer may provide a better habitat for different lineages of symbiont, which either migrate to or compete for them. Since the different zones of these foraminifera are distinct in terms of their cellular contents (McEnery and Lee 1981), this is also a reasonable hypothesis.

Multiple distantly related Symbiodinium lineages exist within an individual foraminifer and show a distinct concentric pattern of distribution. These facts raise new questions about the basic biology of soritid foraminifera and how they relate to the overall reef community. These findings highlight the fact that the host itself is an environment, and that the relationship between symbiont and host is subject to multiple ecological forces.

Factors that determine the symbiont assemblage found in foraminifera

Three factors have been suggested to explain the symbiont specificity seen in soritid foraminifera (Garcia-Cuetos et al. 2005): recognition of the symbiont by the host, vertical transmission of the symbiont, and localized coevolution of the holobiont. Here, this model is built upon and broadened by identifying six factors that determine which symbionts are found in a foraminiferan host.

\section{Mode of symbiont transmission}

The mode of symbiont transmission in soritid foraminifera is dependent upon the life cycle of the host. Soritid foraminifera have a paratrimorphic life cycle, with both sexual and asexual reproductive phases (Kloos and Macgillavry 1978; Zohary et al. 1980; Fujita et al. 2000). In this type of life cycle, a lineage can go through multiple rounds of asexual reproduction. Symbionts are transmitted vertically, from mother to daughter cells, until eventually the host lineage undergoes meiosis to form haploid individuals (gamonts). When these gamonts reach maturity, they produce gametes. The gametes are too small to contain or otherwise transmit symbionts, so this newly diploid zygote (agamont) must adopt symbionts anew from the environment (Lee and Anderson 1991).

The paratrimorphic life cycle offers foraminifera a potential benefit in its flexibility. Vertical transmission can be beneficial since it maintains fidelity with a well-suited symbiont, aligning the interests of the partners (Herre et al. 1999). Horizontal transmission allows a shift to a new symbiont pool, advantageous during times of environmental change (Douglas 1998; Rowan 1998). Thus, a paratrimorphic life cycle allows a strategy where both of these forces can act within a single system.

\section{Symbiont availability from the environment}

Soritid foraminifera have a dynamic relationship with their benthic environment, transporting materials to and from their cell body with rhizopodia. Living foraminifera typically collect benthic microorganisms and detritus around their margins. Whether or not adult foraminifera can acquire new symbionts from their environment is unknown, though zygotes certainly must. Thus, the habitat preferences of different types of Symbiodinium may help determine which types are found in foraminifera. Free-living planktic 
and benthic strains of Symbiodinium have been cultured and identified (Coffroth et al. 2006). Research increasingly focuses on directly characterizing free-living populations of Symbiodinium, especially their relationship to populations in hospite (Manning and Gates 2008). Yet, much remains to be learned about the biogeography and autecology of the alga in its free-living state.

\section{Recognition of symbionts by the host}

In systems with horizontal transmission, the host must encounter free-living symbionts at the boundary between host and external environment. Recognition represents a gateway where only certain genotypes of symbiont (which presumably express idiosyncratic cell surface molecules) avoid digestion by the host. In coral hosts, initial steps have been taken toward understanding the molecular underpinnings which determine recognition of Symbiodinium (Reynolds et al. 2000; Yuyama et al. 2005; RodriguezLanetty et al. 2006a; Deboer et al. 2007). In foraminifera, molecular factors have been discovered which are important in diatom symbiont recognition (Chai and Lee 1999), but the antibodies used in these experiments do not bind to Symbiodinium cells (Lee and Reyes 2006); no other studies have further addressed this question for soritid foraminifera. Hypotheses that explain the distribution of Symbiodinium in foraminifera must take into account the potential for recognition, especially given the evidence for symbiont specificity in foraminifera (Garcia-Cuetos et al. 2005; Pochon and Pawlowski 2006). Since the clades C, F, and H together are monophyletic, the data presented here cannot reject the hypothesis that these symbionts share some common attribute which allows their recognition by foraminifera.

\section{Regulation by the host: the internal environment}

After a symbiont enters the host, the host must have some way to regulate the symbiont population. An array of regulation mechanisms have been proposed and studied in corals, operating either by controlling reproduction rates of, selectively destroying, or expelling unwanted symbionts (Gates et al. 1992; Falkowski et al. 1993; Baghdasarian and Muscatine 2000; Dunn et al. 2002, Dunn and Weis 2009). Such post-phagocytic winnowing mechanisms may be responsible for the pattern of the distribution of symbiont types found in the foraminifera in this study. Symbiont type distribution is influenced by location within the host cell (Fig. 4b), which suggests intracellular regulation.

\section{Symbiont competition within the host}

Whenever mixed symbiont types occur within a host, potential conflict arises between the interests of the host and the competing symbionts (Frank 1996). Competition and virulence can be important factors in determining which symbiont type(s) will ultimately be found in a host (Sachs and Wilcox 2006). Certain types may compete more successfully within a particular host or region within a host. If foraminifera do not selectively regulate symbiont populations, then competitive interactions between symbiont types may help explain their distribution within the host's internal environment.

\section{Holobiont fitness}

A particular host-symbiont pairing is most successful when the fitness interests of the partners are aligned (Herre et al. 1999; Sachs et al. 2004). Holobiont fitness by definition is an increase in the abundance of a particular host/symbiont pair (Zilber-Rosenberg and Rosenberg 2008). It is possible that in some environments, a holobiont consisting of a host with multiple symbiont types is more fit than one with a single type. Since all of the foraminifera examined in this study contained multiple symbiont types, perhaps they have a fitness advantage over those with only one symbiont type in this particular reef environment.

Acknowledgments We would like to thank The Cushman Foundation and UC Berkeley Department of Integrative Biology and Museum of Paleontology for their support, Xavier Pochon, Mary Alice Coffroth, Todd LaJeunesse, John J. Lee, Ellen Simms, Scott Santos, George Roderick, Sean Rovito, and the UCMP community for helpful discussion and insight. We thank Heather Kelly for advice on the manuscript, and Dan Afzal of the Wildlife Conservation Society and John Aini of Ailan Awareness for their help with logistics in PNG.

Open Access This article is distributed under the terms of the Creative Commons Attribution Noncommercial License which permits any noncommercial use, distribution, and reproduction in any medium, provided the original author(s) and source are credited.

\section{References}

Apprill AM, Gates RD (2007) Recognizing diversity in coral symbiotic dinoflagellate communities. Mol Ecol 16:1127-1134

Baghdasarian G, Muscatine L (2000) Preferential expulsion of dividing algal cells as a mechanism for regulating algalcnidarian symbiosis. Biol Bull 199:278-286

Baker AC (2003) Flexibility and specificity in coral-algal symbiosis: diversity, ecology, and biogeography of Symbiodinium. Annual Review of Ecology Evolution and Systematics 34:661-689

Baker AC, Romanski AM (2007) Multiple symbiotic partnerships are common in scleractinian corals, but not in octocorals: comment on Goulet (2006). Mar Ecol Prog Ser 335:237-242

Buddemeier RW, Fautin DG (1993) Coral bleaching as an adaptive mechanism. Bioscience 43:320-326

Carlos AA, Baillie BK, Maruyama T (2000) Diversity of dinoflagellate symbionts (zooxanthellae) in a host individual. Mar Ecol Prog Ser 195:93-100 
Castresana J (2000) Selection of conserved blocks from multiple alignments for their use in phylogenetic analysis. Mol Biol Evol 17:540-552

Chai JY, Lee JJ (1999) Initial recognition of endosymbiotic diatom surface antigens by the larger foraminifer Amphistegina lobifera. Symbiosis 26:39-53

Clement M, Posada D, Crandall KA (2000) TCS: a computer program to estimate gene genealogies. Mol Ecol 9:1657-1659

Coffroth MA, Santos SR (2005) Genetic diversity of symbiotic dinoflagellates in the genus Symbiodinium. Protist 156:19-34

Coffroth MA, Lewis CF, Santos SR, Weaver JL (2006) Environmental populations of symbiotic dinoflagellates in the genus Symbiodinium can initiate symbioses with reef cnidarians. Curr Biol 16:R985-R987

Correa AMS, Baker AC (2009) Understanding diversity in coral-algal symbiosis: a cluster-based approach to interpreting fine-scale genetic variation in the genus Symbiodinium. Coral Reefs 28: 81-93

Deboer ML, Krupp DA, Weis VM (2007) Proteomic and transcriptional analyses of coral larvae newly engaged in symbiosis with dinoflagellates. Comp Biochem Physiol Part D-Genomics Proteomics 2:63-73

Douglas AE (1998) Host benefit and the evolution of specialization in symbiosis. Heredity 81:599-603

Doyle WL, Doyle MM (1940) The structure of zooxanthellae. Pap Tortugas Lab Carnegie Inst Wash 32

Dunn SR, Weis VM (2009) Apoptosis as a post-phagocytic winnowing mechanism in a coral-dinoflagellate mutualism. Environ Microbiol 11:268-276

Dunn SR, Bythell JC, Le Tissier MDA, Burnett WJ, Thomason JC (2002) Programmed cell death and cell necrosis activity during hyperthermic stress-induced bleaching of the symbiotic sea anemone Aiptasia sp. J Exp Mar Biol Ecol 272:29-53

Edgar RC (2004) MUSCLE: multiple sequence alignment with high accuracy and high throughput. Nucleic Acids Res 32:1792-1797

Falkowski PG, Dubinsky Z, Muscatine L, McCloskey L (1993) Population-control in symbiotic corals. Bioscience 43:606-611

Fautin DG, Buddemeier RW (2004) Adaptive bleaching: a general phenomenon. Hydrobiologia 530:459-467

Frank SA (1996) Host-symbiont conflict over the mixing of symbiotic lineages. Proc R Soc B 263:339-344

Fujita K, Nishi H, Saito T (2000) Population dynamics of Marginopora kudakajimensis Gudmundsson (Foraminifera: Soritidae) in the Ryukyu Islands, the subtropical northwest Pacific. Mar Micropaleontol 38:267-284

Garcia-Cuetos L, Pochon X, Pawlowski J (2005) Molecular evidence for host-symbiont specificity in soritid Foraminifera. Protist 156:399-412

Gates RD, Baghdasarian G, Muscatine L (1992) Temperature stress causes host cell detachment in symbiotic cnidarians implications for coral bleaching. Biol Bull 182:324-332

Herre EA, Knowlton N, Mueller UG, Rehner SA (1999) The evolution of mutualisms: exploring the paths between conflict and cooperation. Trends Ecol Evol 14:49-53

Huelsenbeck JP, Ronquist F (2001) MRBAYES: Bayesian inference of phylogenetic trees. Bioinformatics (Oxf) 17:754-755

Kinzie RAIII, Chee GS (1979) The effect of different zooxanthellae on the growth of experimentally reinfected hosts. Biol Bull 156:315-327

Kloos D, Macgillavry HJ (1978) Reproduction and life cycle of Sorites-Orbiculus Foraminifer. Geol Mijnb 57:221-225

LaJeunesse TC, Bhagooli R, Hidaka M, DeVantier L, Done T, Schmidt GW, Fitt WK, Hoegh-Guldberg O (2004) Closely related Symbiodinium spp. differ in relative dominance in coral reef host communities across environmental, latitudinal and biogeographic gradients. Mar Ecol Prog Ser 284:147-161
Langer MR, Lipps JH (1995) Phylogenetic incongruence between dinoflagellate endosymbionts (Symbiodinium) and their host foraminifera (Sorites): small-subunit ribosomal RNA gene sequence evidence. Mar Micropaleontol 26:179-186

Langer MR, Silk MT, Lipps JH (1997) Global ocean carbonate and carbon dioxide production: the role of reef foraminifera. J Foraminifer Res 27:271-277

Lee JJ, Anderson OR (1991) Biology of foraminifera. Academic Press, London

Lee JJ, Reyes D (2006) Initial studies of dinoflagellate symbiont recognition in Soritinae. Symbiosis 42:89-92

Lobban CS, Schefter M, Simpson AGB, Pochon X, Pawlowski J, Foissner W (2002) Maristentor dinoferus n. gen., n. sp., a giant heterotrich ciliate (Spirotrichea: Heterotrichida) with zooxanthellae, from coral reefs on Guam, Mariana Islands. Mar Biol (Berl) 140:411-423

Loram JE, Boonham N, O'Toole P, Trapido-Rosenthal HG, Douglas AE (2007) Molecular quantification of symbiotic dinoflagellate algae of the genus Symbiodinium. Biol Bull 212:259-268

Manning MM, Gates RD (2008) Diversity in populations of freeliving Symbiodinium from a Caribbean and Pacific reef. Limnol Oceanog 53:1853-1861

McEnery ME, Lee JJ (1981) Cytological and fine structural studies of 3 species of symbiont bearing larger Foraminifera from the Red Sea. Micropaleontology (NY) 27:71-83

Mieog JC, van Oppen MJH, Cantin NE, Stam WT, Olsen JL (2007) Real-time PCR reveals a high incidence of Symbiodinium clade $\mathrm{D}$ at low levels in four scleractinian corals across the Great Barrier Reef: implications for symbiont shuffling. Coral Reefs 26:449-457

Muller-Merz E, Lee JJ (1976) Symbiosis in the larger foraminiferan Sorites marginalis (with notes on Archaias spp.). J Protozool 23:390-396

Pochon X, Pawlowski J (2006) Evolution of the soritids-Symbiodinium symbiosis. Symbiosis 42:77-88

Pochon X, Pawlowski J, Zaninetti L, Rowan R (2001) High genetic diversity and relative specificity among Symbiodinium-like endosymbiotic dinoflagellates in soritid foraminiferans. Mar Biol (Berl) 139:1069-1078

Pochon X, LaJeunesse TC, Pawlowski J (2004) Biogeographic partitioning and host specialization among foraminiferan dinoflagellate symbionts (Symbiodinium; Dinophyta). Mar Biol (Berl) 146:17-27

Pochon X, Garcia-Cuetos L, Baker AC, Castella E, Pawlowski J (2007) One-year survey of a single Micronesian reef reveals extraordinarily rich diversity of Symbiodinium types in soritid foraminifera. Coral Reefs 26:867-882

Posada D, Crandall KA (1998) Modeltest: testing the model of DNA substitution. Bioinformatics (Oxf) 14:817-818

Reynolds WS, Schwarz JA, Weis VM (2000) Symbiosis-enhanced gene expression in cnidarian-algal associations: cloning and characterization of a cDNA, sym32, encoding a possible cell adhesion protein. Comp Biochem Physiol A-Mol Integr Physiol 126:33-44

Rodriguez-Lanetty M (2003) Evolving lineages of Symbiodinium-like dinoflagellates based on ITS1 rDNA. Mol Phylogenet Evol 28:152-168

Rodriguez-Lanetty M, Krupp DA, Weis VM (2004) Distinct ITS types of Symbiodinium in Clade C correlate with cnidarian/ dinoflagellate specificity during onset of symbiosis. Mar Ecol Prog Ser 275:97-102

Rodriguez-Lanetty M, Phillips WS, Weis VM (2006a) Transcriptome analysis of a cnidarian-dinoflagellate mutualism reveals complex modulation of host gene expression. BMC Genomics 7:11

Rodriguez-Lanetty M, Wood-Charlson EM, Hollingsworth LL, Krupp DA, Weis VM (2006b) Temporal and spatial infection dynamics 
indicate recognition events in the early hours of a dinoflagellate/ coral symbiosis. Mar Biol 149:713-719

Rowan R (1998) Diversity and ecology of zooxanthellae on coral reefs. J Phycol 34:407-417

Rowan R (2004) Coral bleaching: thermal adaptation in reef coral symbionts. Nature 430:742

Rowan R, Knowlton N, Baker A, Jara J (1997) Landscape ecology of algal symbionts creates variation in episodes of coral bleaching. Nature 388:265-269

Sachs JL, Wilcox TP (2006) A shift to parasitism in the jellyfish symbiont Symbiodinium microardiaticum. Proc R Soc B 273: 425-429

Sachs JL, Mueller UG, Wilcox TP, Bull JJ (2004) The evolution of cooperation. Q Rev Biol 79:135-160

Sambrook J, Fritsch EF, Maniatis T (1989) Molecular cloning a laboratory manual, vol 1, 2 and 3, 2nd edn. Cold Spring Harbor, New York, USA

Sampayo EM, Franceschinis L, Hoegh-Guldberg O, Dove S (2007) Niche partitioning of closely related symbiotic dinoflagellates. Mol Ecol 16:3721-3733

Sampayo EM, Dove S, LaJeunesse TC (2009) Cohesive molecular genetic data delineate species diversity in the dinoflagellate genus Symbiodinium. Mol Ecol 18:500-519
Stat M, Carter D, Hoegh-Guldberg O (2006) The evolutionary history of Symbiodinium and scleractinian hosts: symbiosis, diversity, and the effect of climate change. Perspect Plant Ecol Evol Syst 8:23-43

Thornhill DJ, LaJeunesse TC, Kemp DW, Fitt WK, Schmidt GW (2006) Multi-year, seasonal genotypic surveys of coral-algal symbioses reveal prevalent stability or post-bleaching reversion. Mar Biol (Berl) 148:711-722

Thornhill DJ, Lajeunesse TC, Santos SR (2007) Measuring rDNA diversity in eukaryotic microbial systems: how intragenomic variation, pseudogenes, and PCR artifacts confound biodiversity estimates. Mol Ecol 16:5326-5340

Yuyama I, Hayakawa H, Endo H, Iwao K, Takeyama H, Maruyama $\mathrm{T}$, Watanabe $\mathrm{T}$ (2005) Identification of symbiotically expressed coral mRNAs using a model infection system. Biochem Biophys Res Commun 336:793-798

Zilber-Rosenberg I, Rosenberg E (2008) Role of microorganisms in the evolution of animals and plants: the hologenome theory of evolution. FEMS Microbiol Rev 32:723-735

Zohary T, Reiss Z, Hottinger L (1980) Population dynamics of Amphisorus-Hemprichii Foraminifera in the Gulf of Elat Aqaba Red Sea. Eclogae Geol Helv 73:1071-1094 